\title{
Discussions of Risk and New Approaches to Responsible Research and Innovation
}

\author{
Christopher Coenen
}

Published online: 1 March 2018

(C) Springer Science+Business Media B.V., part of Springer Nature 2018

As you may have noticed, the December issue of our journal came out without an editorial. I therefore wish to start by rather belatedly extending my best wishes to you for 2018 !

Before introducing the current issue, I would like to look back at the final issue of 2017. It was certainly the "most nano" issue for quite a long time, with all its articles addressing topics in nanoscience and nanotechnology except Migle Laukyte's instructive review of an important recent publication on social robots. As in the current issue, the majority of the articles dealt with different aspects of risk and safety.

The December issue even featured an entire special section on "Safer by Design in the Nano-Field", guestedited by Claudia Schwarz-Plaschg, Angela Kallhoff, and Iris Eisenberger. Since December, the fine articles published in this section have attracted quite wide notice, as our download statistics show. In their (as usual, freely available) introduction, the guest editors provided an overview of the articles published in this interdisciplinary special section and information about the background to their selection, as well as reflecting on the debate about how to make nanomaterials safer by design. I was particularly impressed by the editors' thoughtful, well-balanced discussion of the political aspects of discourse on safety by design, and fully agree

C. Coenen $(\triangle)$

Institute for Technology Assessment and Systems Analysis (ITAS), Karlsruhe Institute of Technology (KIT), POB 3640, 76021 Karlsruhe, Germany

e-mail: christopher.coenen@kit.edu with them that risk-related decisions are inherently political choices. Like them, I would like to see more research into what they have called the "hidden politics" of safety by design projects and "the political visions they reinforce", and we will be happy to publish more research along these lines in our journal.

I was also particularly happy to at last see the publication of an article by Mikael Johansson and Åsa Boholm that explores how Swedish and US nanoscientists view the risks posed by nanomaterials. This is a great example of an empirically rich, conceptually convincing ethnographic study of scientists' understanding of the risks of nanomaterials, and can be read most profitably together with the special section on safety by design. Our journal is always interested in such insightful ethnographic analyses. The article by Johansson and Boholm also nicely complemented a study by Rider Foley, Arnim Wiek, and Braden Kay in which the authors presented the new Collaborative Onsite Technology Exploration (COTE) approach, and the results of its use in the Gateway district in Phoenix. Nanoscientists were brought together with community stakeholders in order to look for solutions to challenges such as a renewable energy supply, water contamination, and public health issues.

Last but by no means least, two pieces that focus on Scandinavia, and discussions about responsible research and innovation (RRI) both helped to make the December issue a real highlight among the issues of our journal dedicated largely or wholly to nanosciences and nanotechnologies. In their article, Lilian van Hove and Fern Wickson remind us of the crucial role the nanofield has 
played, and still plays, in discourse on and for RRI practices. They describe an empirical study that explored the potential for RRI within nanosafety research in Norway and Denmark, and identify various practical barriers and cultural differences that inhibit the enactment of RRI within research laboratories. They argue for significant changes to the enactment of RRI characteristics at the level of individual research scientists, stressing that such changes are needed in order for RRI (as currently imagined and promoted) to become an integral mode of scientific culture. It is noteworthy that - as the authors pointed out out to me - this study would not have been possible without very close interaction with the nanoscience community, and the NorNanoReg project in particular, a Norwegian national initiative that is working on the development of a common approach to the regulatory testing of manufactured nanomaterials. Anders Strand's article concentrates entirely on Norway and a major, five-year national project that is seeking to develop a deeper understanding of the behaviour of nanomaterials in the body, with an emphasis on biodegradable nanoparticles for cancer diagnostics and targeted cancer drug delivery. Like van Hove and Wickson in their article, Strand also uses the results of his analysis as the starting point for a broader discussion of how RRI can be better facilitated.

The December issue thus offers not only a rare collection of fascinating insights into, and fine-grained analyses of, the nanofield and the discussions in and around it, but also thought-provoking arguments about the difficulties and potential of RRI more generally, both as they are perceived inside research institutions and as they impact on the role of nanoscience in society.

The series of excellent articles on the nanofield is continued in the present issue, testifying to this field's societal relevance, and the richness of philosophical, social-scientific, political, and other studies about it and its place(s) in society. This time, however, the emphasis is on regulatory, policy, and civil society issues.

In their article, Ineke Malsch, Martin Mullins, Elena Semenzin, Alex Zabeo, Danail Hristozov, and Antonio Marcomini, all from SUN, an EU-funded project on sustainable nanotechnologies, present analyses of, and reflections on, a decision support system developed under the SUN project that is intended to improve the handling of nanomaterials in global value chains for many different products. While this decision support system has been primarily developed for confidential use by risk and sustainability managers inside a company or a consortium, the authors also see potential for to be deployed as an open access decision support system in negotiations on international agreements concerning trade in nanomaterials. Their analysis and reflections are also based on the results of stakeholder engagement activities conducted as part of the project, as well as literature and internet sources suggested by representatives from stakeholder groups, including civil society organisations (CSOs).

Hannot Rodríguez provides us with an analysis of the governance of nanotechnology risk aspects in the European Union (EU), and uses this example to elaborate broader reflections on safety discourse in highly promoted and contested areas of innovation. Once again, the RRI concept is a key issue in this fine article. While pointing out that, in his view largely thanks to the European Parliament, the EU has taken on a vanguard role in activities relating to the governance of nanotechnology, the author also makes it plain that all the key political bodies in the EU assume nanotechnology development is controllable, and take it for granted that both the massive industrial use of nanomaterials, and high levels of environmental and health protection are compatible. Rodríguez believes these assumptions about controllability are contestable in the light of the technology's socio-economic and cultural aspects. Discussing RRI, he argues that more ambitious approaches to socio-technical safety seem to be seriously constrained by current innovation ideologies and the economic imperatives of global capitalism.

In their article on risk governance in the nanofield, Kristen Lyons and Naomi Smith examine the use of nanoparticles in the food system in Australia, and sharply criticise the regulatory body Food Standards Australia New Zealand (FSANZ). They build on the results of research that was commissioned by the CSO Friends of the Earth. Apart from their argument about the governance of nanoparticles in the Australian food system, the article is therefore also of interest with a view to the increasingly intense discussions about, and activities around, CSO-commissioned and CSO-led research. Lyons and Smith conclude that, within the current food governance framework and against the backdrop of a paucity of impact science, civil society can play a vital role in what they call the "democratisation" of food systems.

Our journal is also well-known for having given prominence to a wide range of other new and emerging 
technoscientific fields over more than ten years. As someone who had the honour of coordinating the recently concluded EU-funded project SYNENERGENE, from which the SYNENERGENE network (https://www.synenergene.eu/) evolved, I am particularly happy about the fact that, among these subjects, synthetic biology has been featuring very prominently in our pages for well over a decade as well. In the present issue, two articles draw attention to countries that are not covered so frequently by research on this field or, for that matter, other fields of new and emerging technoscience. Zinatul Ashiqin Zainol and Nabeel Mahdi Althabhawi explore what the legal concept of a "person skilled in the art" could mean in the context of synthetic biology in an analysis that focuses on Malaysia, but also incorporates an Iraqi perspective. In particular, the authors discuss the term "person" in this context as it relates to the question of differences between individual researchers and research teams. In his article, Franc Mali, a member of the SYNENERGENE network, looks at Slovenia as a small country where some remarkable early activity in synthetic biology took place. Since there is a dearth of empirical studies on the perspectives of relevant stakeholders in countries where synthetic biology is still in the process of emergence, Mali's research on the points of view articulated by various stakeholder groups in Slovenia will be of interest for anyone seeking to understand innovation processes in emerging fields of technoscience. Surveying the policy framework, ethico-legal discourse, and the issues of biosafety and biosecurity, he analyses why Slovenia missed early opportunities to foster the domestic development of this field.

I would like to remind you that you are all always welcome to submit "critical discussion notes" (of up to about 5000 words) to us, not just about risk aspects, but also about any of the many other politically or otherwise controversial topics discussed in our journal. Together with research papers proper and book reviews, these peer-reviewed discussion notes are one of the key elements of the content published in NanoEthics. Studies of New and Emerging Technologies as a forum for open discussion about all kinds of aspects of science and technology in society. Given the importance of new and currently emerging forms of technoscience and their applications in the economy, politics, and other areas, we will soon need even more open, inclusive discussions of this sort, and our journal exists to support them. 